\title{
Effects of morphine on the human sphincter of Oddi
}

\author{
J F HELM, R P VENU, J E GEENEN, W J HOGAN, W J DODDS, \\ J TOOULI, AND R C ARNDORFER
}

From The Digestive System Research Center and the Departments of Medicine and Radiology, Medical College of Wisconsin, Milwaukee, Wisconsin, USA

SUMmary The effects of morphine on intraluminal pressures recorded from the sphincter of Oddi (SO) at endoscopic retrograde cholangiopancreatography in 19 patients who were without evidence of biliary or pancreatic disease were studied. Morphine was given in four successive doses of $2 \cdot 5$, $2.5,5$, and $10 \mu \mathrm{g} / \mathrm{kg}$ iv at five minute intervals. Morphine in subanalgesic doses increased the frequency of SO phasic pressure waves to a maximum of $10-12 / \mathrm{min}$, caused the phasic waves to occur simultaneously along the sphincter segment, increased phasic wave amplitude from 72 (26) (SE) to $136(31) \mathrm{mmHg}$, and increased SO basal pressure from 10 (1) to 29 (9) $\mathrm{mmHg}(\mathrm{p}<0 \cdot 05)$. The effects of morphine on the SO are mediated by more than one opioid receptor type, as naloxone competitively antagonised the increase in phasic wave frequency induced by morphine, but did not affect the increase in SO basal pressure elicited by morphine. When given after naloxone, morphine decreased phasic wave amplitude, an inhibitory effect that is normally masked by morphine's dominant naloxone sensitive excitatory effect. Mu receptors do not appear to be involved in control of spontaneous SO motor function, as naloxone alone did not affect SO motor activity. The excitatory effects of morphine on the SO are not mediated by cholinergic nerves, as they were not blocked by atropine. Cholinergic nerves, however, may have a role in regulating spontaneous SO motor function because atrophine alone depressed phasic wave activity and basal pressure. Although morphine does cause 'spasm' of the human SO, its effects are more complex than is commonly believed.

Morphine and other opiod analgesics are believed to cause 'spasm' of the human sphincter of Oddi (SO).' SO spasm has been inferred from the observations that common bile duct pressure is increased ${ }^{2-5}$ and flow of radiographic contrast into the duodenum is obstructed $^{67}$ after giving an opiod analgesic. These observations were made during elective cholecystectomy or after surgery through a T-tube in the common bile duct. In healthy volunteers, opiod analgesics delay passage of radionuclide into the duodenum during cholescintigraphy. ${ }^{\circ}$ Although these observations indicate that opioid analgesics cause functional obstruction of common bile duct

Address for correspondence: James F Helm, MD, Medical College of Wisconsin, Division of Gastroenterology, Froedtert Memorial Lutheran Hospital, 9200 West Wisconsin Avenue, Milwaukee, WI 53226, USA Received for publication 11 May 1988. outflow, the effects of opioid analgesics on the SO were not measured directly.

Recent developments in manometric instrumentation now permit accurate recording of intraluminal pressure from the human SO at endoscopic retrograde cholangiopancreatography (ERCP). ${ }^{9-12}$ The SO is characterised manometrically by prominent phasic pressure waves superimposed on a basal pressure that is several $\mathrm{mmHg}$ above the common bile duct pressure. A majority of SO phasic pressure waves propagate antegrade towards the duodenum, although retrograde and simultaneous phasic wave sequences occur as well. In this study, the effects of morphine on intraluminal pressure recorded from the SO in patients who were without evidence of biliary or pancreatic disease were determined. We also investigated the mechanisms by which morphine acts on the human SO. 


\section{Methods}

\section{PATIENTS}

Nineteen patients undergoing ERCP and SO manometry for suspected biliary or pancreatic disease, but in whom the biliary and pancreatic ducts were found to be normal were studied and who were considered to be within a close approximation of normal. The subjects included 18 women and one man, 25 to 73 years of age. The studies were approved by the Human Research Review Committee of the Medical College of Wisconsin.

Intraluminal pressures were recorded from the SO by a manometric catheter passed through the biopsy channel of a fibreoptic endoscope. The catheter was a single extruded polyethylene tube with an outer diameter of $1.7 \mathrm{~mm}$ and three lumens, each $0.5 \mathrm{~mm}$ in diameter (Arndorfer Medical Specialties, Greendale, Wisconsin). ${ }^{12}$ Each lumen ended in a lateral recording orifice. The three orifices were spaced at $2 \mathrm{~mm}$ intervals, with the most distal orifice located $5 \mathrm{~mm}$ from the end of the catheter. Starting from the most distal orifice and continuing proximally, the catheter was marked with eight black rings, $2 \mathrm{~mm}$ apart, to permit determination of the depth of catheter insertion into the SO. Duodenal intraluminal pressure was recorded continuously by a single lumen Teflon catheter taped to the endoscope so that the recording orifice was positioned at the level of the biopsy channel opening. The Teflon catheter had an outer diameter of $1.7 \mathrm{~mm}$ and an inner diameter of $0.8 \mathrm{~mm}$. During pressure recording, each catheter lumen was perfused with water at a rate of $0.25 \mathrm{ml} / \mathrm{min}$ by a minimally-compliant pneumohydraulic capillary infusion system (Arndorfer Medical Specialties, Greendale, Wisconsin).

Immediately before endoscopy, all patients were sedated with a $10-15 \mathrm{mg}$ iv diazepam, an agent that does not affect SO motor function. ${ }^{13}$ After completion of the diagnostic ERCP, the intraductal contrast medium was allowed to drain into the duodenum. The manometric catheter was then passed through the endoscope, the papilla recannulated, and the catheter advanced into the common bile duct (CBD). The catheter was then withdrawn across the SO in 1-2 mm increments, using the black rings on the catheter as a reference, until all three recording orifices were stationed within the SO. During withdrawal of the catheter from the CBD, the SO was identified manometrically by the appearance of prominent phasic pressure waves superimposed on a basal pressure that was several $\mathrm{mmHg}$ greater than the CBD pressure. All three recording orifices were maintained within the SO throughout the manometric studies. After a five minute control period, seven subjects were given $1 \mathrm{ml} 0.9 \% \mathrm{NaCl}$ iv, followed by morphine sulphate in four successive doses of $2 \cdot 5,2 \cdot 5,5$, and $10 \mu \mathrm{g} / \mathrm{kg}$ iv at five minute intervals. The resultant cumulative morphine doses after each injection were $2 \cdot 5,5,10$, and $20 \mu \mathrm{g} / \mathrm{kg}$. In two other groups of six subjects each, morphine was given after naloxone, $0.4 \mathrm{mg}$ iv, or after atropine sulphate, $12 \mu \mathrm{g} / \mathrm{kg}$ iv, respectively. At the end of the manometric procedure, contrast medium was introduced through one of the lumens of the manometric catheter to verify that the catheter had been advanced into the CBD.

The manometric tracing from the middle recording orifice was chosen for scoring SO basal pressure and phasic wave activity. Previous studies have not shown significant differences in SO basal pressure or phasic wave amplitude among the three recording sites. ${ }^{12}$ The SO basal pressure was referenced to duodenal pressure by subtracting the end expiratory duodenal pressure from the baseline SO pressure between phasic pressure waves. The mean basal pressure was calculated for each five minute recording period. The amplitude and frequency of phasic pressure waves were determined for the same five minute recording periods, and mean values were calculated. The amplitude of phasic pressure waves was calculated by subtracting the basal SO pressure from the peak phasic wave pressure. Sphincter of Oddi phasic pressure waves were classified as occurring simultaneously, or as propagating antegrade towards the duodenum or retrograde away from the duodenum.

STATISTICAL ANALYSIS

Values in the text are expressed as mean (SE). The Student's paired $t$ test was used to test differences within the same group of subjects for statistical significance. Differences between groups of subjects were tested by the Student's unpaired $t$ test.

\section{Results}

In the 19 subjects SO basal pressure was 12 (2) (SE) $\mathrm{mmHg}$ above duodenal pressure. Superimposed on the SO basal pressure were phasic pressure waves that occurred with a frequency of $4.4(0.3) / \mathrm{min}$ (range $2-6 / \mathrm{min}$ ). The amplitude of phasic pressure waves was 73 (12) $\mathrm{mmHg}$ above SO basal pressure. Antegrade propagation of phasic pressure waves towards the duodenum accounted for the majority of wave sequences, although subjects also exhibited retrograde or simultaneous phasic wave sequences, or both.

Figure 1 shows an example of the effect of intravenous morphine on intraluminal pressures recorded from the human SO. In small cumulative doses of 2.5 or $5 \mu \mathrm{g} / \mathrm{kg}$ iv, morphine increased the frequency of 

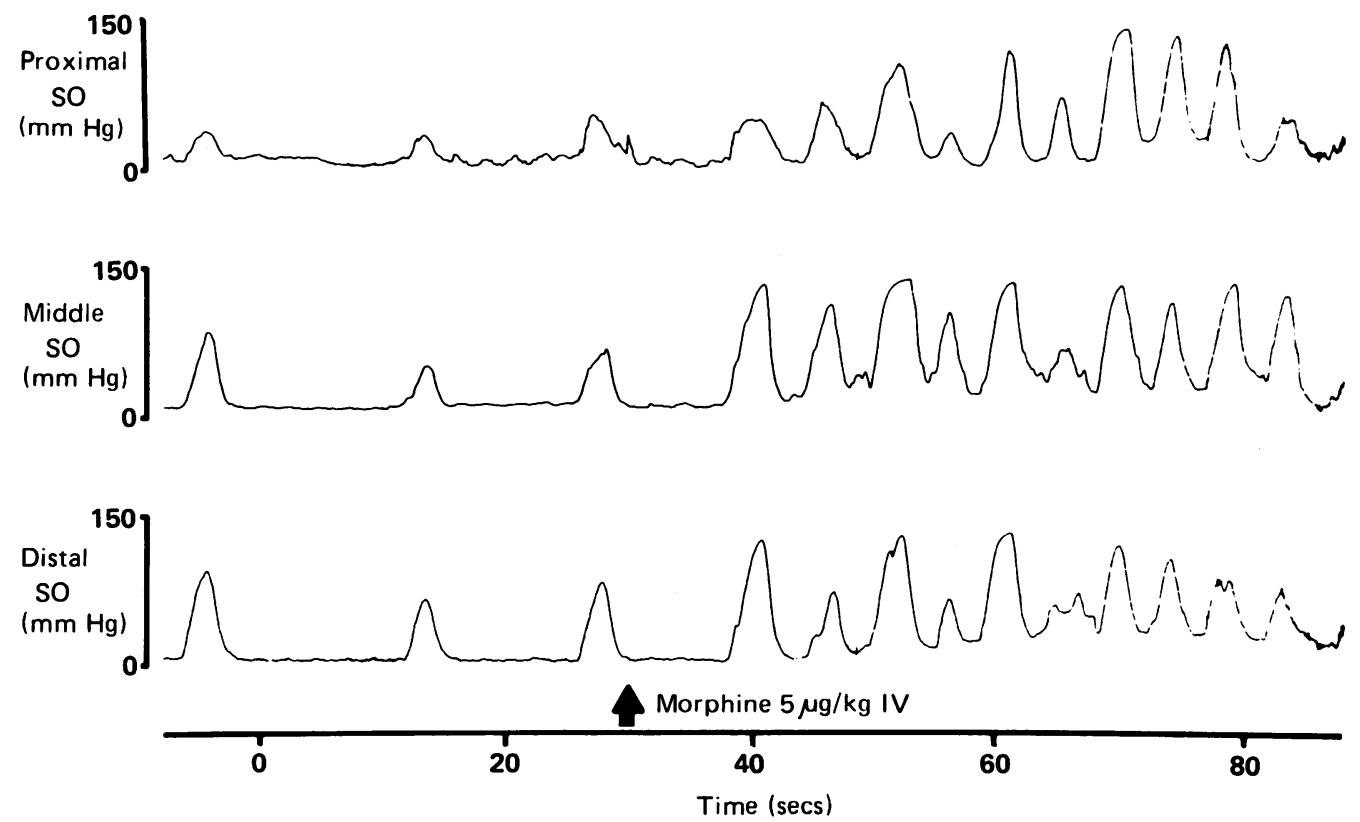

Fig. 1 Effect of a $5 \mu \mathrm{g} / \mathrm{kg}$ iv cumulative dose of morphine on intraluminal pressure recorded from the human SO. Morphine caused a prompt increase in the frequency and amplitude of phasic pressure waves, as well as in the basal pressure. Although not easily seen in this Figure, morphine also caused the phasic waves to occur simultaneously along the sphincter segment, whereas phasic waves propagated primarily in the antegrade direction before morphine was given.

phasic pressure waves to a maximum of 10-12-min and caused the phasic wave sequences to become simultaneous, but did not affect the mean phasic wave amplitude (Fig. 2). In these small doses, morphine did not increase the mean SO basal pressure. In larger cumulative doses of 10 or $20 \mu \mathrm{g} / \mathrm{kg}$ iv, morphine did not cause any further increase in the frequency of phasic pressure waves, but increased the amplitude of the phasic waves and the SO basal pressure. Pressures recorded from the SO were independent from the concurrently recorded duodenal pressure, before, and after morphine.

Naloxone, $0.4 \mathrm{mg}$ iv, did not affect spontaneous SO phasic wave activity or basal pressure (Fig. 3). Naloxone completely blocked the increase in frequency of phasic pressure waves elicited by small cumulative morphine doses of 2.5 or $5 \mu \mathrm{g} / \mathrm{kg}$ iv, however, and caused a parallel shift of the dose response curve towards the right. When given after naloxone, the largest cumulative morphine dose of 20 $\mu \mathrm{g} / \mathrm{kg}$ iv significantly decreased the amplitude of phasic pressure waves. In contrast, this dose of morphine given by itself increased phasic wave amplitude. Naloxone did not have a significant effect on the increase in SO basal pressure elicited by morphine in large cumulative doses of 10 or $20 \mu \mathrm{g} / \mathrm{kg}$ iv.
Atropine in a dose of $12 \mu \mathrm{g} / \mathrm{kg}$ iv depressed spontaneous SO phasic wave activity and basal pressure (Fig. 4). In four subjects, atropine abolished the SO basal pressure, while phasic pressure waves were eliminated in three of these subjects. Atropine, however, did not prevent a substantial increase in the SO basal pressure or in the frequency and amplitude of phasic pressure waves in response to morphine.

\section{Discussion}

The findings of this study show that the human $\mathrm{SO}$ is exquisitely sensitive to morphine. In doses substantially lower than those used to obtain analgesia, morphine increased the frequency and amplitude of SO phasic pressure waves, as well as the basal pressure. The frequency of phasic pressure waves, however, was more sensitive to morphine than was the phasic wave amplitude or the basal pressure. In doses that did not significantly increase either phasic wave amplitude or basal pressure, morphine increased the frequency of phasic waves to the maximum. The mechanism for this greater sensitivity of phasic wave frequency to morphine is unknown.

Naloxone alone had no effect on spontaneous SO phasic wave activity or basal pressure. This finding suggests that mu opioid receptors are not involved in 

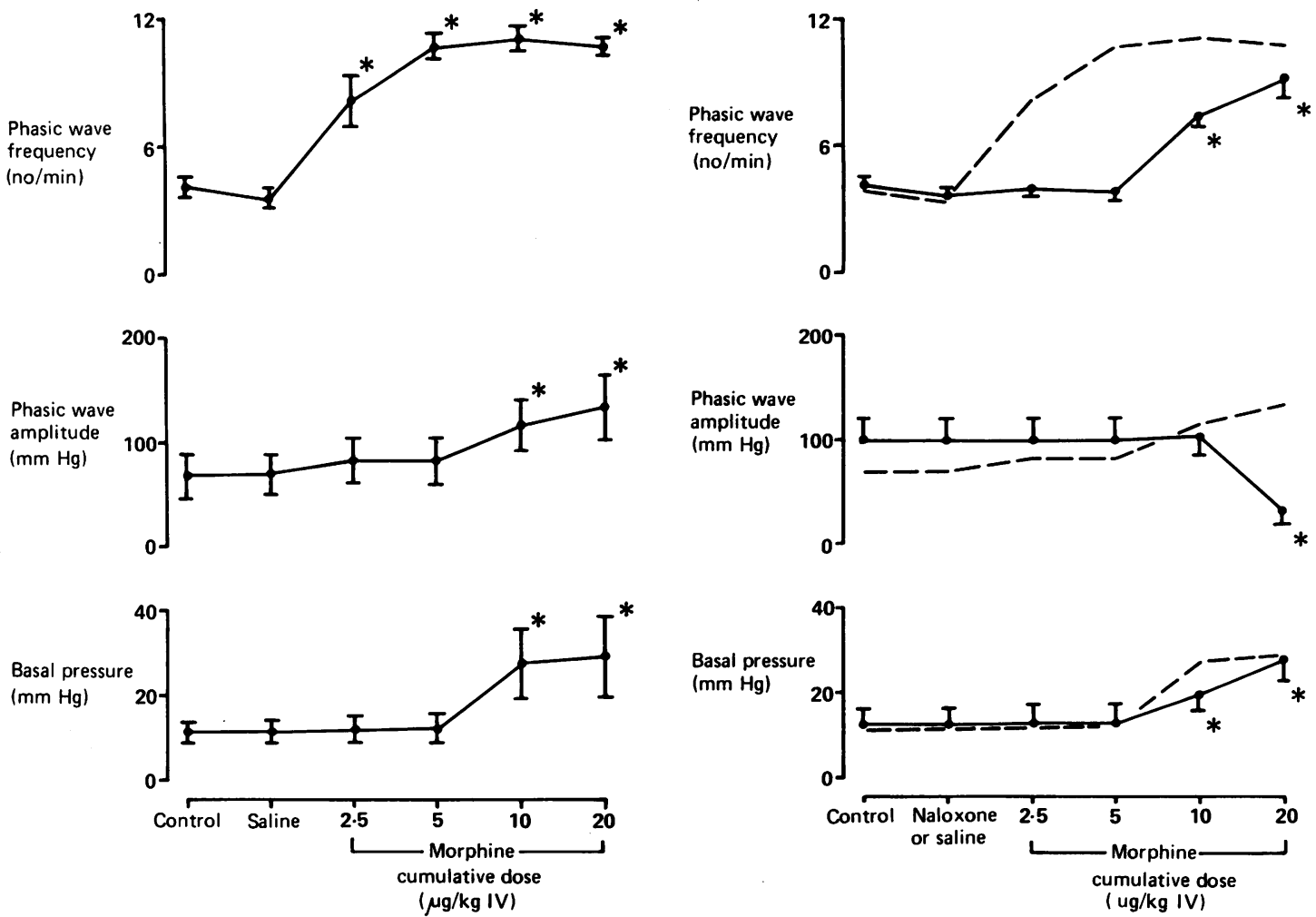

Fig. 2 Effect of morphine on SO phasic waves and basal pressure in seven subjects. Small cumulative morphine doses of 2.5 or $5 \mu \mathrm{g} / \mathrm{kg}$ iv increased phasic wave frequency to a maximum, but did not affect mean phasic wave amplitude or basal pressure. Larger cumulative morphine doses of 10 or $20 \mathrm{ug} / \mathrm{kg}$ iv increased phasic wave amplitude and basal pressure. Values are expressed as mean (SE). ${ }^{*} p<0.05$, greater than values after saline alone.

spontaneous SO motor function. The increase in frequency of SO phasic pressure waves after morphine is likely mediated by mu receptors, however, because naloxone antagonised the increase in phasic wave frequency elicited by morphine. The parallel shift of the morphine dose response curve towards the right after naloxone suggests that naloxone is acting as a competitive antagonist.

Evidence exists that morphine can act at different opioid receptors to produce both excitatory and inhibitory effects. Jacquet showed that the inhibitory effect of morphine on the rat vas deferens is mediated by a stereospecific opioid receptor that is blocked by naloxone, whereas its excitatory effect is mediated by a non-stereospecific receptor that is not blocked by naloxone ${ }^{14}$ In the SO in man, naloxone blocked the increase in amplitude of phasic pressure waves that occurred after morphine, and thereby unmarked the

Fig. 3 Effect of morphine on SO phasic waves and basal pressure after naloxone, $0.4 \mathrm{mg}$ iv, in six subjects (solid lines). For comparison, dashed lines show the mean response to morphine in the seven subjects who were given saline instead of naloxone. Naloxone alone did not affect spontaneous SO motor function. Naloxone antagonised the increase in phasic wave frequency induced by morphine, causing a parallel shift of the dose response curve towards the right. When given after naloxone, morphine in a $20 \mu \mathrm{g} / \mathrm{kg}$ dose decreased phasic wave amplitude, whereas morphine alone increased phasic wave amplitude. Naloxone did not affect the increase in basal pressure elicited by morphine. Values are expressed as mean or mean $(S E)$. ${ }^{*} p<0.05$, different from values after naloxone alone.

inhibitory effect of morphine on phasic wave amplitude. The dominant excitatory effect of morphine on phasic wave amplitude is likely mediated by mu receptors, whereas the inhibitory effect appears to be mediated by a non-mu opioid receptor. Although naloxone antagonised the excitatory effects of morphine on SO phasic wave activity, naloxone had no effect on the increase in basal pressure caused by morphine. The increase in basal pressure after morphine may be mediated by an opioid receptor other than the mu receptor.

In the opossum, spontaneous SO phasic contractions are myogenic in origin, but enteric nerves or 

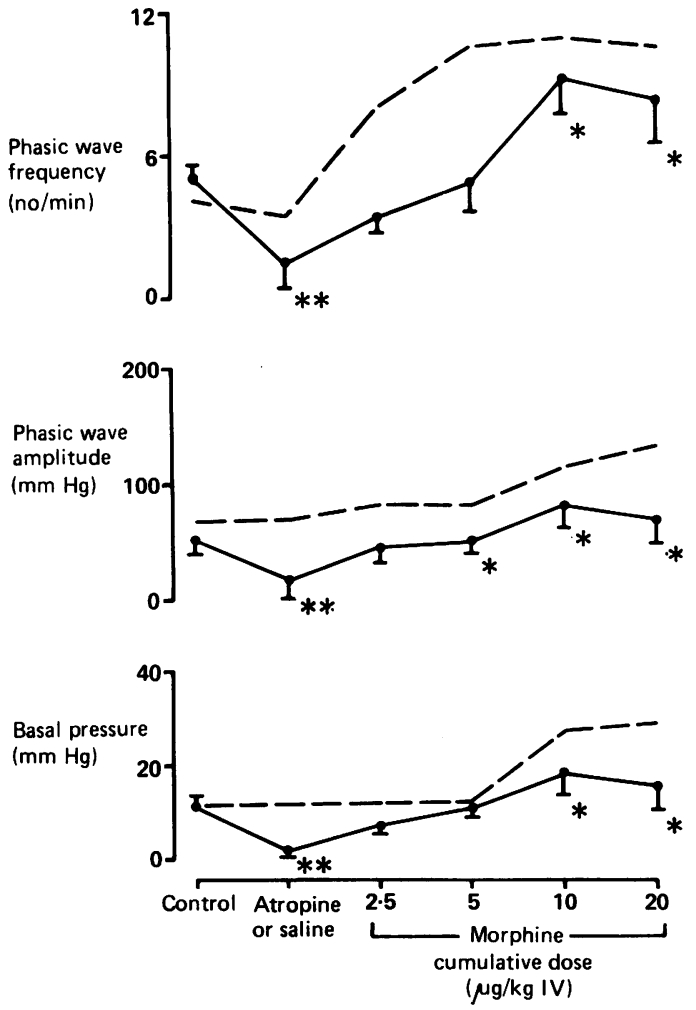

Fig. 4 Effect of morphine on SO phasic waves and basal pressure after atropine, $12 \mu \mathrm{g} / \mathrm{kg}$ iv, in six subjects (solid lines). For comparison, dashed lines show the mean response to morphine in the seven subjects who were given saline instead of atropine. Atropine alone depressed or abolished spontaneous $S O$ phasic wave activity and basal pressure, but did not block the excitatory effects of morphine. Values are expressed as mean or mean $(S E) .{ }^{* *} p<0.05$, less than control values. ${ }^{*} p<0 \cdot 05$, greater than values after atropine alone.

hormones may modulate the contraction frequency. ${ }^{15}{ }^{16}$ In vitro studies of the opossum SO have shown the existence of cholinergic excitatory nerves, as well as non-cholinergic inhibitory nerves whose presence is unmarked by cholinergic blockade. ${ }^{17}$ In the SO in man, atropine depressed or abolished spontaneous phasic wave activity and basal pressure, thereby suggesting that cholinergic excitatory nerves have an important role in regulating spontaneous SO motor function. Although we have not shown the presence of inhibitory nerves in the human SO, it is probable that non-cholinergic inhibitory nerves are present and contribute to the depression of spontaneous motor activity after cholinergic blockage. Atropine did not block the excitatory effects of morphine on SO phasic waves and basal pressure, thereby indicating that these effects are not likely mediated by cholinergic nerves.
Radiographic observations in man and the opossum suggest that the SO may function as a peristaltic pump to actively expel fluid from the sphincter segment into the duodenum. ${ }^{1518-20}$ Analogous to cardiac ventricular filling, the SO segment fills with fluid from the CBD only during the diastolic interval between phasic sphincter contractions. Outflow of fluid from the CBD is reduced or arrested when (1) the frequency of phasic contractions increases sufficiently to compromise diastolic filling of the sphincter segment, (2) phasic contractions propagate retrograde or occur simultaneously along the length of the sphincter segment, or (3) passive filling of the sphincter segment is prevented by a SO basal pressure that exceeds the CBD pressure. Morphine could cause functional obstruction of the SO by all three of these mechanisms, because it increased the frequency of SO phasic pressure waves to supraphysiologic values, caused the phasic waves to become simultaneous, and substantially increased the SO basal pressure. Naloxone did not fully reverse the obstructive effects of morphine, because despite antagonism of increased phasic wave activity, naloxone did not affect the increase in SO basal pressure induced by morphine. In the absence of phasic SO contractions, fluid outflow from the CBD is solely passive and dependent on resistance to flow through the sphincter segment.$^{20}$ Thus, abolition of spontaneous SO phasic waves and basal pressure by atropine would be expected to promote passive fluid flow through the spincter segment.

In summary, morphine does indeed cause 'spasm' of the human SO, as evidenced by the increase in SO basal pressure after morphine administration. The effects of morphine on the SO, however, are more complex than previously supposed. Morphine has excitatory effects on SO phasic wave activity, as well as on basal pressure. Furthermore, the effects of morphine on the SO are mediated by more than one opioid receptor type. In the case of phasic wave amplitude, the response to morphine represents the net effect of activating excitatory and inhibitory opioid receptors. Although cholinergic nerves do not appear to mediate the effects of morphine on the human SO, they may modulate spontaneous SO motor activity.

\section{References}

1 Jaffe JH, Martin WR. Opioid analgesics and antagonists. In: Gilman AG, Goodman LS, Rall TW, Murad F, eds. The pharmacological basis of therapeutics. New York: Macmillan Publ Co, 1985: 503-4.

2 Dedrick DF, Tanner WW, Bushkin FL. Common bile duct pressure during enflurane anesthesia. Effects of 
morphine and subsequent naloxone. Arch Surg 1980; 115: 820-2.

3 Economou G. Ward-McQuaid JN. A cross-over comparison of the effect of morphine, pethidine, and phenazocine on biliary pressure. Gut 1971; 12: 218-21.

4 Greenstein AJ, Kaynan A, Singer A, Dreiling DA. A comparative study of pentazocine and meperidine on the biliary passage pressure. Am J Gastroenterol 1972; 58: 417-27.

5 Tuominen $\mathrm{M}$. Comparison of the effect of anileridine and pethidine on the intracholedochal pressure during constant fluid perfusion. Acta Anaesthesiol Scand 1976; 20: $177-82$.

6 Goldberg HI. Operative and postoperative cholecystocholangiography. Semin Roentgenol 1978; 11: 203-11.

7 Chessick KC, Black S. Hoye SJ. Spasm and operative cholangiography. Arch Surg 1975; 110: 53-7.

8 Joehl R. Koch KL. Nahrwold DL. Opioid drugs cause bile duct obstruction during hepatobiliary scans. $A m \mathrm{~J}$ Surg 1984; 147: 134-8.

9 Csendes A, Kruse A, Funch-Jensen P. Oster MJ, Ornsholt J, Amdrup E. Pressure measurements in the biliary and pancreatic duct systems in controls and in patients with gallstones, previous cholecystectomy, or common bile duct stones. Gastroenterology 1979; 77: 1203-10.

10 Geenen JE, Hogan WJ, Dodds WJ, Stewart ET, Arndorfer RC. Intraluminal pressure recording from the human sphincter of Oddi. Gastroenterology 1980; 78: 317-24.

11 Carr-Locke DL, Gregg JA. Endoscopic manometry of pancreatic and biliary sphincter zones in man: basal results in healthy volunteers. Dig Dis Sci 1981; 26: 7-15.
12 Toouli J, Geenen JE, Hogan WJ, Dodds WJ, Arndorfer RC. Sphincter of Oddi motor activity: a comparison between patients with common bile duct stones and controls. Gastroenterology 1982; 82: 111-7.

13 Nebel OT. Manometric evaluation of the papilla of Vater. Gastrointest Endosc 1975; 21: 126-8.

14 Jacquet YF. Excitatory and inhibitory effects of opiates in the rat vas deferens: a dual mechanism of opiate action. Science 1980; 210: $95-7$.

15 Toouli J, Dodds WJ, Honda R, et al. Motor function of the opossum sphincter of Oddi. J Clin Invest 1983; 71: 208-20.

16 Helm JF, Dodds WJ, Christensen J, Sarna SK. Control mechanism of spontaneous in vitro contractions of the opossum sphincter of Oddi. Am J Physiol 1985; 249 (Gastrointest Liver Physiol 12): G572-9.

17 Helm JF, Christensen J. Dodds WJ, Sarna S. Intrinsic innervation of the opossum sphincter of Oddi (SO). Gastroenterology 1983; 84: 1185.

18 Caroli J, Porcher P, Pequignot G, Delattre M. Contribution of cineradiography to study of the function of the human biliary tract. Am J Dig Dis 1960; 5: 677-96.

19 Hess W. Manometry and radiography in the biliary system during surgery. In: Demling L, Classen M, eds. Endoscopic sphincterotomy of the papilla of Vater. Proceedings of the International Workshop of the World Congress of Gastroenterology, Munich, 1976. Stuttgart: Thieme, 1978: 19-23.

20 Dodds WJ, Hogan WJ, Geenen JE. Motility of the biliary system. In: Wood JD, ed. Handbook of physiology. Sec 6: Alimentary canal. Motility and circulation. Bethesda, Maryland: American Physiological Society. (In press). 